\title{
Two year maintenance of efficacy and safety of infliximab in the treatment of ankylosing spondylitis
}

\author{
J Braun, J Brandt, J Listing, A Zink, R Alten, G Burmester, E Gromnica-lhle, \\ H Kellner, M Schneider, H Sörensen, H Zeidler, J Sieper
}

See end of article for authors' affiliations

Correspondence to: Professor J Braun, Rheumazentrum Ruhrgebiet, Landgrafenstr 15, 44652 Herne, Germany; J.Braun@ RheumazentrumRuhrgebiet.de

Accepted 20 June 2004 Published Online First 23 September 2004

\begin{abstract}
Objective: To obtain results of the second year extension of an original 3 month randomised, placebo controlled trial (and the 1 year extension study) assessing the use of infliximab, a monoclonal antibody to tumour necrosis factor $\alpha$, for the treatment of patients with ankylosing spondylitis (AS).

Methods: Of the 54 patients with AS who completed the first year of the study, 52 continued to receive infliximab $5 \mathrm{mg} / \mathrm{kg}$ every 6 weeks up to week 102. The primary end point was the proportion of patients achieving at least $50 \%$ improvement from baseline in the Bath AS Disease Activity Index (BASDAI) at week 102. Other assessments included patient and physician global assessments, quality of life as assessed by Short Form-36, Bath AS Functional Index, Bath AS Metrology Index, and C reactive protein (CRP).

Results: Improvement in signs and symptoms of AS seen during the first year of the study was sustained during the second year. Forty nine patients (71\% of 69 enrolled patients and 49/52 (94\%) patients who started year 2) completed the study up to week 102. Thirty (58\%) patients achieved at least $50 \%$ improvement from baseline in the BASDAl score at week 102. Scores for other efficacy assessments were similar at weeks 54 and 102. Median CRP levels remained low at weeks 54 and 102 (3.9 and $4.3 \mathrm{mg} / \mathrm{l}$, respectively). Side effects during the second year of the study were similar to those of the first year of treatment with infliximab.

Conclusions: Patients with AS treated for 2 years with infliximab $5 \mathrm{mg} / \mathrm{kg}$ exhibited a good and durable clinical response.
\end{abstract}

A nkylosing spondylitis (AS) is a chronic, immune mediated, inflammatory disease that affects the sacroiliac joints, axial skeleton, entheses, and, occasionally, peripheral joints. Until recently, treatment of AS has typically consisted of a chronic regimen of non-steroidal antiinflammatory drugs (NSAIDs) and physiotherapy. Although NSAIDs can relieve pain to allow for increased spinal movement, they appear to have little effect on the underlying inflammatory process unless used daily, as indicated by one recent study. ${ }^{1}$ Disease modifying antirheumatic drugs (DMARDs) that are used successfully in patients with rheumatoid arthritis are only partially effective in treating patients with AS. ${ }^{2}$

Agents that target the proinflammatory cytokine tumour necrosis factor $\alpha(\mathrm{TNF} \alpha)$ have recently been identified as a possible alternative to existing treatments for AS. $^{3}$ In 2002, we reported the results of a 12 week, double blind, placebo controlled study of infliximab in patients with AS. ${ }^{4}$ Patients receiving infliximab showed significant improvement in measurements of disease activity, physical function, and quality of life compared with those receiving placebo. ${ }^{4}$ This response was shown to be durable for up to a full year in an open label extension, during which patients in the placebo group crossed over at week 12 , and all patients subsequently received infusions of infliximab $5 \mathrm{mg} / \mathrm{kg}$ every 6 weeks. ${ }^{5}$ This open label phase of the study was extended for a second year to assess further the long term efficacy and safety of infliximab. Here, we present findings from the second year of the study.

\section{PATIENTS AND METHODS}

Patients and study protocol

The eligibility criteria and the study design of the 12 week, randomised, placebo controlled phase of the study ${ }^{4}$ and the l year extension study ${ }^{5}$ have been reported previously. Sixty nine patients with active AS participated in the original study. Active AS was defined as a Bath Ankylosing Spondylitis Disease Activity Index (BASDAI) score of at least 4 and a spinal pain assessment score of at least 4 (on a numerical rating scale ranging from 0 to 10). Throughout the 2 year study, concomitant DMARDs and oral corticosteroids were not permitted. NSAID use was permitted, and the doses of NSAIDs could be reduced during the study. However, NSAID doses could not be increased over the baseline level.

Patients who completed the first year of the study were eligible to continue with the extension study up to week 102. Patients who chose to participate in the second year of the study received open label infusions of infliximab $5 \mathrm{mg} / \mathrm{kg}$ every 6 weeks beginning with the week 54 infusion. The study drug was manufactured by Centocor, Inc and was packaged and labelled for the study by Essex Pharma (Munich, Germany).

The study was conducted at eight centres in Germany, all of which had patients who participated in the second year of the study. The local independent ethics committees approved the original study protocol and the second year extension. All patients who chose to participate in the second year of the study provided written informed consent.

\footnotetext{
Abbreviations: AS, ankylosing spondylitis; ASAS, Assessment in Ankylosing Spondylitis; BASDAl, Bath Ankylosing Spondylitis Disease Activity Index; BASFI, Bath AS Functional Index; BASMI, Bath AS Metrology Index; CRP, $C$ reactive protein; DMARDs, disease modifying antirheumatic drugs; ESR, erythrocyte sedimentation rate; ITT, intention to treat; NSAIDs, non-steroidal anti-inflammatory drugs; SF-36, Short Form-36; TNF $\alpha$, tumour necrosis factor $\alpha$
} 


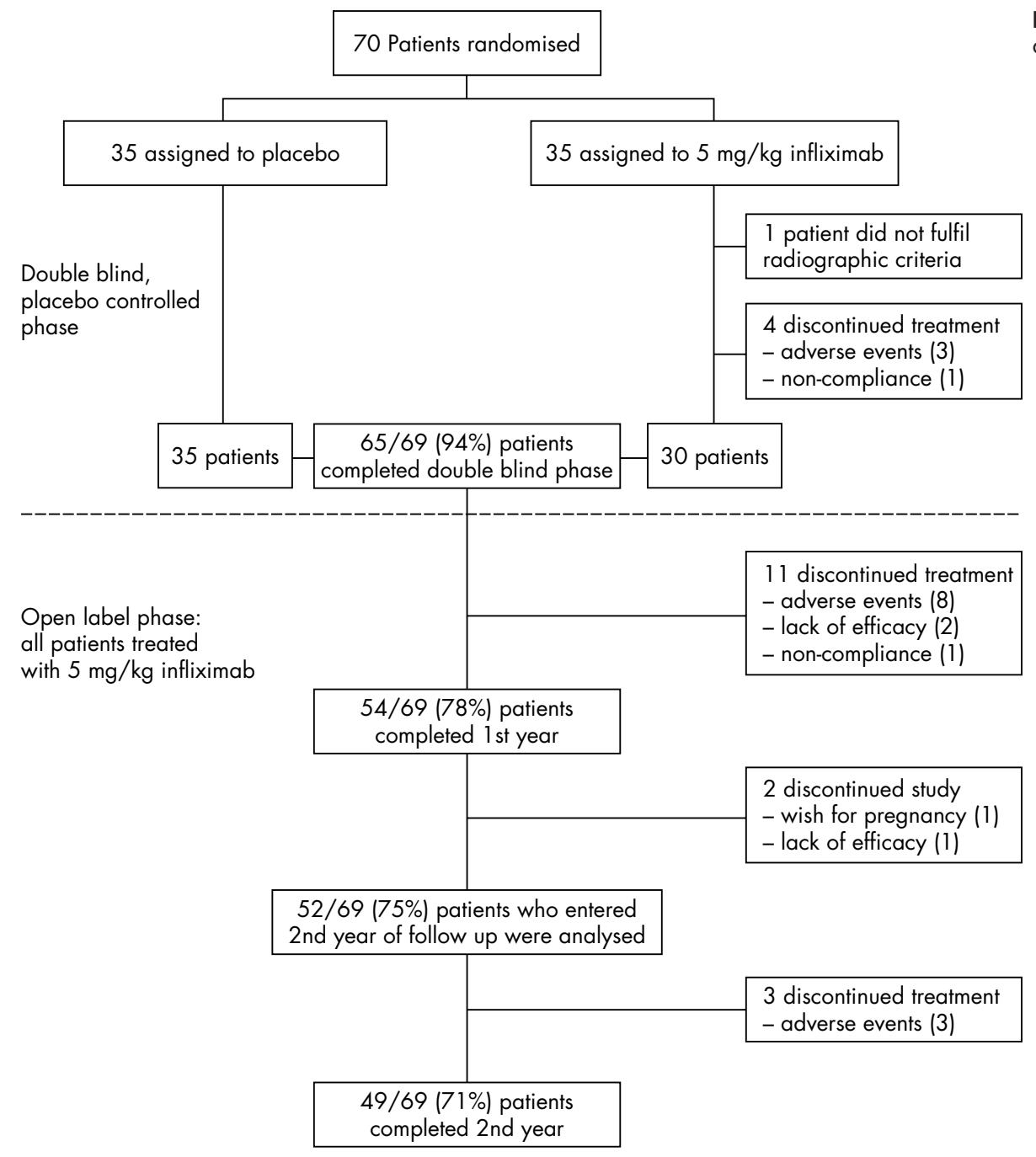

Figure 1 Summary of patient disposition up to week 102.

\section{Assessments}

Disease activity was assessed using the BASDAI, which consists of six questions relating to fatigue, spinal pain, peripheral arthritis, enthesitis, and morning stiffness. ${ }^{6}$ The Bath AS Functional Index (BASFI), a 10 item questionnaire which assesses the patient's ability to conduct daily activities, was used to measure physical function. ${ }^{7}$ The Bath AS Metrology Index (BASMI) was used to grade mobility of the spine and hip by measuring tragus to wall, lumbar flexion, cervical rotation, lumbar side flexion, and intermalleolar distance on a scale of 1 to $10 .^{8}$ Patient and physician global disease assessments and assessments of spinal pain were measured using a numerical rating scale ranging from 0 to 10 . Health related quality of life was assessed using the Short Form-36 (SF-36) instrument. ${ }^{9}$ The scoring algorithm of the Medical Outcome Trust ${ }^{10}$ was used to calculate the SF-36 physical and mental component summary scores.

Partial remission was assessed using the criteria of the Assessment in Ankylosing Spondylitis (ASAS) Working Group. ${ }^{11}$ Furthermore, the ASAS $40 \%$ and ASAS 5 out of 6 criteria recently proposed were applied..$^{12}$ ASAS $40 \%$ improvement is defined as an improvement of at least $40 \%$ and an absolute improvement of at least 2 units (on a 0-10 scale) in at least three domains and no deterioration in the fourth remaining domain. The four following domains were used in the assessment: patient's global assessment, pain, function (represented by the BASFI score), and inflammation (represented by the mean of the two morning stiffness scales of the BASDAI). To meet the ASAS 5 out of 6 criteria a $20 \%$ improvement in any five of the following six domains is required: the four domains used for ASAS $40 \%$ and the following two domains: acute phase reactants (assessed by $\mathrm{C}$ reactive protein $(\mathrm{CRP})$ ) and spinal mobility (assessed by the BASMI score).

\section{Statistical analysis}

Two different groups were analysed: the intention to treat (ITT) group and the second year study group. In the ITT analysis, data for all patients randomised who fulfilled the inclusion criteria ( $n=69$, fig 1 ) were included. In the analysis based on the second year study group, data for 52 patients who participated in the second year of follow up were included (fig 1). The primary efficacy end point was the proportion of patients achieving at least $50 \%$ improvement from baseline to week 102 in the BASDAI score. Secondary end points were the proportion of patients at week 102 achieving $20 \%$ or $70 \%$ improvement from baseline in the BASDAI score, the proportion of patients achieving the ASAS $40 \%$, ASAS 5 out of 6 criteria and partial remission, as well as a change from baseline to week 102 in spinal pain, the BASDAI score, BASFI score, BASMI score, SF-36 physical and mental component summary scores, CRP, and erythrocyte sedimentation rate (ESR). Patients who withdrew were 

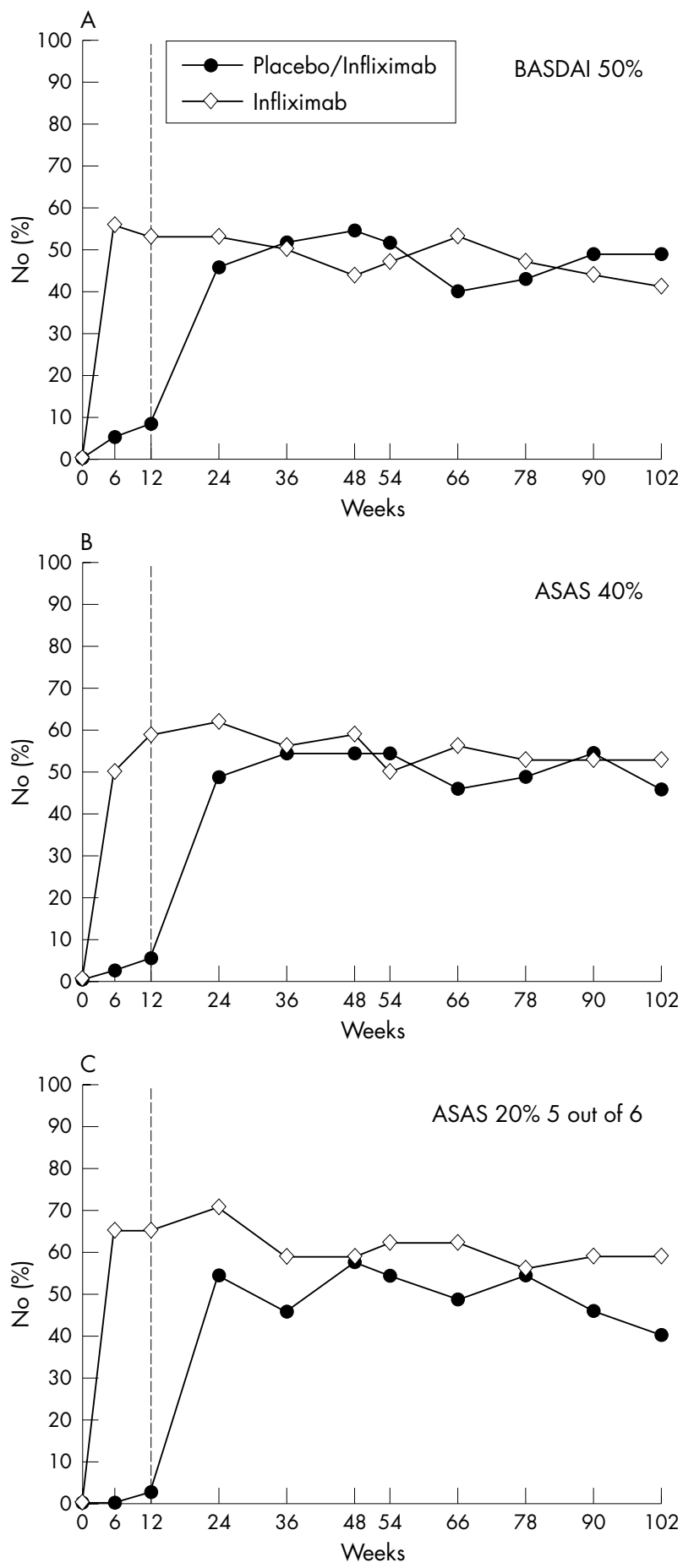

Figure 2 Maintenance of response to infliximab treatment (ITT study group), as assessed by (A) at least $50 \%$ improvement in the BASDAI; (B) at least $40 \%$ improvement in the criteria of the ASAS working group; and (C) improvement of at least $20 \%$ in the ASAS 5 out of 6 criteria for AS.

considered to be BASDAI/ASAS non-responders for every missing visit. To calculate the means for the second year study group, data for the last observation were carried forward to the end point for patients who stopped prematurely. To compare mean differences between different times (week $0 v$ week 102, week $54 v$ week 102), the paired $t$ test was applied. When distributions were skewed (CRP, ESR) the corresponding non-parametric test (Wilcoxon test) was used. The McNemar test was used to compare frequencies between

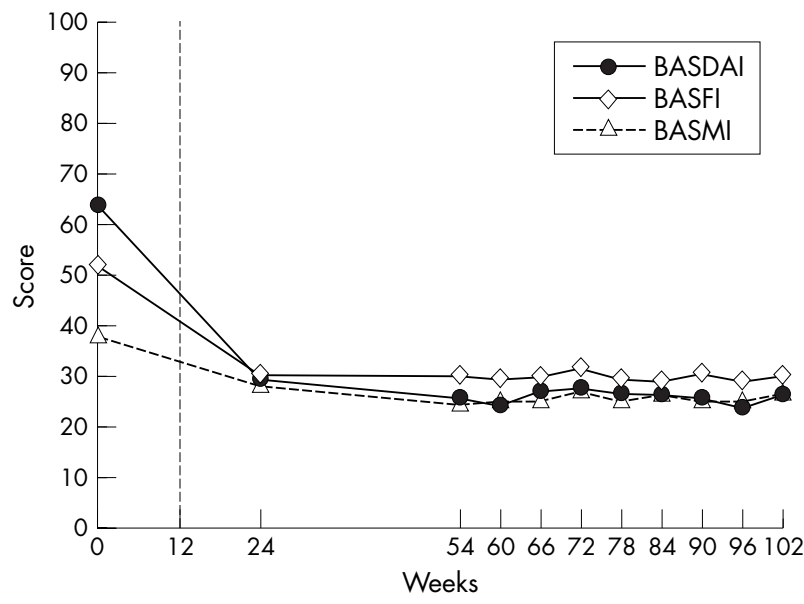

Figure 3 Sustained improvement of patients of the second year study group over 2 years of follow up, as assessed by the mean BASDAI, mean BASFI, and mean BASMI.

different times. Furthermore, a recently proposed nonparametric dropout test was applied to investigate if the dropout could be considered as a random sample from the ITT study group in respect of the selected parameters. ${ }^{13}$

\section{RESULTS}

Results for the first 3 months ${ }^{4}$ and the first year ${ }^{5}$ of this study have been reported previously. Fifty four patients (78\%) completed the study up to week 54 . Of the patients who completed the first year of the study, 52 patients (96\%) chose to continue with the second year (second year study group). Two patients withdrew from the study. One patient withdrew for personal reasons (wanted a pregnancy) and one reported lack of efficacy. Sixty four per cent of the patients were men with a mean age of 38.8 years and mean weight of $73.0 \mathrm{~kg}$. Forty nine of the original 69 patients $(71 \%)$ completed the entire 102 week study, representing $94 \%$ of the patients who started year 2 . Three patients discontinued the study during the second year of treatment because of adverse events (fig 1).

\section{Efficacy}

ITT analysis

Similar and stable response rates over 2 years were observed in the analysis of the data of the complete ITT population (fig 2). Although each patient who discontinued was counted as non-responder, no significant decrease in the response rates of the primary efficacy end point (BASDAI 50\% response) was seen for the two treatment groups or for the total group (fig 2A). At week 54, 47\% of the patients in the infliximab and $51 \%$ of the patients in the placebo infliximab group achieved a 50\% improvement in the BASDAI score from baseline. At week 102 these figures were $41 \%$ and $49 \%$, respectively (fig 2A). The evaluation of the ASAS $40 \%$ criteria and the ASAS 5 out of 6 criteria among the 69 patients who fulfilled the inclusion criteria also showed comparable levels of response at each time over 2 years of follow up (figs $2 \mathrm{~B}$ and C).

\section{Analysis of the second year study group}

Thirty of $52(58 \%)$ patients achieved the primary efficacy end point of at least a $50 \%$ reduction of the BASDAI score from baseline to week 102. This level of response was similar to that seen at week 54 when 33/52 (63\%) patients achieved at least $50 \%$ improvement in the BASDAI score. The BASDAI $50 \%$ response was consistent over the entire second year of the study, with 30 or more patients achieving at least $50 \%$ 


\begin{tabular}{|c|c|c|c|c|c|}
\hline \multirow[b]{2}{*}{ Assessment } & \multirow[b]{2}{*}{ Baseline } & \multirow[b]{2}{*}{ Week 54} & \multirow[b]{2}{*}{ Week 102} & \multicolumn{2}{|l|}{$\mathrm{p}$ Value } \\
\hline & & & & $\begin{array}{l}\text { wk 0 v } \\
\text { wk } 102\end{array}$ & $\begin{array}{l}\text { wk } 54 v \\
\text { wk } 102\end{array}$ \\
\hline \multicolumn{6}{|l|}{ Global disease assessment (VAS) } \\
\hline Patient $(0-10 \mathrm{~cm})$ & $6.9(1.9)$ & $2.8(1.9)$ & $2.6(2.0)$ & $<0.0001$ & 0.39 \\
\hline Physician $(0-10 \mathrm{~cm})$ & $6.3(1.6)$ & $2.2(1.5)$ & $2.0(1.4)$ & $<0.0001$ & 0.14 \\
\hline BASDAI & $6.4(1.4)$ & $2.5(1.7)$ & $2.6(2.0)$ & $<0.0001$ & 0.61 \\
\hline BASFI & $5.2(1.9)$ & $3.0(2.2)$ & $3.0(2.2)$ & $<0.0001$ & 0.88 \\
\hline BASMI & $3.8(2.0)$ & $2.4(2.0)$ & $2.7(2.1)$ & $<0.0001$ & 0.038 \\
\hline CRP (mg/l), median (range) & $21.5(0.9-74.0)$ & $3.9(0-17.8)$ & $4.3(0-42.7)$ & $<0.0001$ & 0.51 \\
\hline ESR $(\mathrm{mm} / 1 \mathrm{st} \mathrm{h})$, median (range) & $25.0(3-88)$ & $8.0(1-70)$ & $7.5(2-70)$ & $<0.0001$ & 0.39 \\
\hline $\begin{array}{l}\text { SF-36 } \\
\text { Physical component }\end{array}$ & $29.3(7.0)$ & $40.6(10.6)$ & $40.9(11.1)$ & $<0.0001$ & 0.73 \\
\hline Mental component & $42.3(12.2)$ & $50.9(8.9)$ & $50.2(9.5)$ & $<0.0001$ & 0.47 \\
\hline
\end{tabular}

improvement at each assessment point. Forty nine (94\%) and $44(85 \%)$ patients achieved at least $20 \%$ improvement in BASDAI at weeks 54 and 102, respectively. The proportions of patients achieving at least a $70 \%$ reduction in BASDAI score from baseline were the same at weeks 54 and $102(22 / 52$ (42\%) patients).

The sustained response observed for the BASDAI was consistent with results obtained for the other clinical assessments of AS (table 1, fig 3). Almost all measures showed a significant change from baseline to week 102 $(p<0.0001)$; as expected, changes from week 54 to week 102 were not significant (table 1). Specifically, the mean BASFI score was 3.0 at both weeks 54 and 102. The mean BASMI scores were 2.4 and 2.7 at weeks 54 and 102, respectively (table 1, fig 3). The individual measures of the BASMI showed no substantial changes during the study (table 2). Patients' and physicians' global disease assessments and physical and mental component summary scores of the SF-36 were similar between weeks 54 and 102 (table 1). The median ESR remained stable $(\leqslant 8.0 \mathrm{~mm} / \mathrm{lst} \mathrm{h})$ between weeks 54 and 102; the median CRP serum level showed a minor increase from $3.9 \mathrm{mg} / \mathrm{l}$ at week 54 to $4.3 \mathrm{mg} / \mathrm{l}$ at week 102 (table 1). Notably, the median CRP remained well below the mean baseline value of $21.5 \mathrm{mg} / \mathrm{l}$.

At week 102, 13 patients (25\%) achieved partial remission-that is, two patients in addition to those who had achieved remission at week 54. Enthesitis was evident in seven patients, which was consistent with findings at

Table 2 The individual aspects of the BASMl, as assessed for the second year study group at baseline $(n=52)$, week 54 , and after 2 years (week 102)

\begin{tabular}{llllll}
\hline & & & \multicolumn{3}{c}{ p Value } \\
\cline { 4 - 6 } BASMI & Baseline & Week 54 & Week 102 & $\begin{array}{l}\text { wk } \mathbf{v} \\
\text { wk 102 }\end{array}$ & $\begin{array}{l}\text { wk 54 v } \\
\text { wk 102 }\end{array}$ \\
\hline Tragus wall distance $<15 \mathrm{~cm}$ & $41(79)$ & $43(83)$ & $39(75)$ & 0.73 & 0.13 \\
Lumbar flexion $>4 \mathrm{~cm}$ & $4(8)$ & $17(33)$ & $12(23)$ & 0.021 & 0.18 \\
Cervical rotation $>70^{\circ}$ & $7(13)$ & $25(48)$ & $20(38)$ & 0.002 & 0.18 \\
Lateral lumbar flexion $>10 \mathrm{~cm}$ & $23(44)$ & $32(62)$ & $32(62)$ & 0.012 & 1.0 \\
Intermalleolar distance $>100 \mathrm{~cm}$ & $30(58)$ & $38(73)$ & $38(73)$ & 0.021 & 1.0 \\
\hline
\end{tabular}

Table 3 Partial remission, enthesitis, and arthritis for the 52 patients who participated in the second year of the study at baseline, week 54 , and week 102, with data about the $95 \%$ confidence interval for each assessed variable

\begin{tabular}{|c|c|c|c|c|c|}
\hline \multirow[b]{2}{*}{ Assessment } & \multirow[b]{2}{*}{ Baseline } & \multirow[b]{2}{*}{ Week 54} & \multirow[b]{2}{*}{ Week 102} & \multicolumn{2}{|l|}{ p Value } \\
\hline & & & & $\begin{array}{l}\text { wk } 0 v \\
\text { wk } 102\end{array}$ & $\begin{array}{l}\text { wk } 54 v \\
\text { wk } 102\end{array}$ \\
\hline \multicolumn{6}{|c|}{ Partial remission } \\
\hline $\begin{array}{l}\text { No }(\%) \\
95 \% \mathrm{Cl}\end{array}$ & 0 & $\begin{array}{l}11(21) \\
(12 \text { to } 34)\end{array}$ & $\begin{array}{l}13(25) \\
(15 \text { to } 38)\end{array}$ & 0.0002 & 0.73 \\
\hline \multicolumn{6}{|l|}{ Enthesitis } \\
\hline $\begin{array}{l}\text { No }(\%) \\
95 \% \mathrm{Cl}\end{array}$ & $\begin{array}{l}23(42) \\
(32 \text { to } 58)\end{array}$ & $\begin{array}{l}7(13) \\
\text { (7 to } 25)\end{array}$ & $\begin{array}{l}7(13) \\
(7 \text { to } 25)\end{array}$ & 0.0004 & 1.00 \\
\hline \multicolumn{6}{|l|}{ Arthritis } \\
\hline $\begin{array}{l}\text { No }(\%) \\
96 \% \mathrm{Cl}\end{array}$ & $\begin{array}{l}18(35) \\
(23 \text { to } 48)\end{array}$ & $\begin{array}{l}1(2) \\
(0 \text { to } 10)\end{array}$ & $\begin{array}{l}6(12) \\
\text { (5 to } 23)\end{array}$ & 0.004 & 0.063 \\
\hline \multicolumn{6}{|c|}{$C R P \leqslant 6 \mathrm{mg} / \mathrm{l}$} \\
\hline $\begin{array}{l}\text { No }(\%) \\
95 \% \mathrm{Cl}\end{array}$ & $\begin{array}{l}12(23) \\
(14 \text { to } 36)\end{array}$ & $\begin{array}{l}43(83) \\
\text { (70 to } 91)\end{array}$ & $\begin{array}{l}41 \text { (79) } \\
\text { (66 to } 88 \text { ) }\end{array}$ & $<0.0001$ & 0.79 \\
\hline
\end{tabular}


Table 4 Disease characteristics at baseline and at the last visit of the drop out; patients not included in the 2 year analysis $(n=17)$

\begin{tabular}{|c|c|c|c|c|}
\hline \multirow[b]{2}{*}{ Assessment } & \multicolumn{2}{|l|}{ At baseline } & \multicolumn{2}{|l|}{ At last visit } \\
\hline & Mean (SD) & p Value* & Mean (SD) & p Value* \\
\hline $\begin{array}{l}\text { Physician global (VAS 0-10) } \\
\text { BASDAI } \\
\text { BASFI } \\
\text { CRP (mg/l), median (range) }\end{array}$ & $\begin{array}{l}6.4(1.3) \\
6.3(11) \\
5.5(2.4) \\
19(3-131)\end{array}$ & $\begin{array}{l}0.85 \\
0.60 \\
0.61 \\
0.88\end{array}$ & $\begin{array}{l}4.0(1.9) \\
5.0(2.0) \\
4.3(3.0) \\
6(1-91)\end{array}$ & $\begin{array}{l}0.03 \\
0.02 \\
0.12 \\
0.04\end{array}$ \\
\hline
\end{tabular}

* In comparison with the $n=52$ patients included in the primary analyses.

Results are shown as mean (SD) unless otherwise stated.

previous times. Peripheral arthritis was reported in six patients, which was an increase of five patients from the number reported at week 54 ( $\mathrm{p}>0.05$; table 3$)$.

By week 54, 17 patients had dropped out of the study (mean (SD) infliximab treatment for 30 (14.4) weeks). The baseline disease characteristics of these patients were similar to those of patients who remained in the study (table 4). At their last visit these patients had, on average, higher values for the BASDAI, physician global assessment, and CRP than those who participated in the second year of follow up. For this reason, results for the complete ITT study group are also provided (figs $2 \mathrm{~A}, \mathrm{~B}$, and $\mathrm{C}$ ).

\section{Adverse events}

During the second year of this study, 47 (90\%) patients reported adverse events (table 5). The most frequently reported events were upper respiratory tract infections $(17 \%)$, rhinitis $(13 \%)$, and herpes simplex $(12 \%)$.

Six patients $(12 \%)$ reported serious adverse events that were considered to be clinically relevant. The events for four of these patients were considered by the investigator to be unrelated to the study drug (osteoporosis, euphoria/syncope,

Table 5 Summary of the adverse events reported for all 52 patients who participated in the second year of the study

\begin{tabular}{ll}
\hline & $\begin{array}{l}\text { Year } 2 \text { study } \\
\text { group (n=52) } \\
\text { No (\%) }\end{array}$ \\
Assessment & $47(90)$ \\
\hline $\begin{array}{l}\text { Patients reporting at least 1 adverse event } \\
\text { Patients who discontinued the study owing to an } \\
\text { adverse event }\end{array}$ & $3(6)$ \\
Patients reporting at least 1 clinically relevant & $6(12)$ \\
serious adverse event & \\
Patients reporting at least 1 treatment related* & $2(4)$ \\
serious adverse event & \\
& \\
Most frequently reported adverse events $\geqslant 5 \%$ of & \\
patients) & \\
Upper respiratory tract infections & \\
Rhinitis & $9(17)$ \\
Herpes simplex & $7(13)$ \\
Influenza-like symptoms & $6(12)$ \\
Pulmonary infection & $5(10)$ \\
Antinuclear factor test positive & $5(10)$ \\
Symptoms associated with infusion & $4(8)$ \\
Hepatic enzymes increased & $4(8)$ \\
Bronchitis & $4(8)$ \\
Headache & $4(8)$ \\
Fatigue & $3(6)$ \\
Dry eyes & $3(6)$ \\
Allergy & $3(6)$ \\
Accidental injury & $3(6)$ \\
Alanine aminotransferase increased & $3(6)$ \\
Menorrhagiat & $3(6)$ \\
Fungal vaginitist & $1(5)$ \\
\hline & $1(5)$ \\
\hline
\end{tabular}

*The determination of an event's relationship to treatment was made by the investigator; tpercentage is based on the population of women only. pancreatitis, and menorrhagia; each in one patient). The patient with osteoporosis, a 32 year old man, was diagnosed by dual energy $x$ ray absorptiometry in the lst year of the study by a routine examination. It could not be ascertained whether the bone density had changed during the study. The patient continued to receive infliximab after the diagnosis. Two serious adverse events (symptoms associated with infusion and musculoskeletal pain, each in one patient) were considered to be possibly related to the study drug. Five other patients reported surgical procedures or rehabilitation measures that were considered to be clinically irrelevant and unrelated to the study drug (for example, correction of the nasal septum, plastic surgery of the patella, treatment at a health resort (two patients), foot operation, and thyroid surgery).

Three patients $(6 \%)$ discontinued infliximab owing to the adverse events reported above. Two of these patients had reactions associated with infusion that led to discontinuation. The third patient stopped treatment after reporting an exacerbation of pre-existing pancreatitis, which the investigator considered to be unrelated to the study treatment.

\section{DISCUSSION}

These data for the 2 year open label extension study of infliximab in patients with AS suggest sustained efficacy and safety of this biological agent. The original randomised, controlled, clinical trial conducted over 3 months ${ }^{4}$ and the 1 year open label phase $e^{5}$ were extended for a second year to investigate further the efficacy and safety of this treatment in patients with severe AS. The high level of response seen during the first year of the study was maintained throughout the second year, with similar proportions of patients achieving the primary end point of at least 50\% improvement in the BASDAI score at week 54 (63\%) and week 102 (58\%). It is especially relevant that patients remained in a state of low disease activity up to week 102, as shown by the clinical assessments made, including the BASDAI, BASFI, BASMI, the global scores, and quality of life (SF-36). Scores for these measures were similar at the 1 and 2 year assessments, indicating continuous improvement of clinical symptoms and a durable clinical response to infliximab. Thus, in patients with AS who were treated continuously using a maintenance regimen with infusions at regular intervals, we did not observe the reduction in efficacy that was reported in patients with Crohn's disease who received infusions at irregular intervals. ${ }^{14}$

Infliximab was generally well tolerated by patients with AS participating in this study. The adverse events seen during the second year of treatment were similar to those reported for the first year and were consistent with the known safety profile of infliximab. There were no more reports of lupuslike syndrome, serious infections, or tuberculosis. Few patients stopped treatment during the second year, and only two patients had infusion related reactions that led to discontinuation. Additionally, the overall discontinuation rate $(8 \%)$ during the second year of the study was lower 
than that seen during the first year of the study $(22 \%)$ and also lower than that seen during the second year of the antiTNF Trial in Rheumatoid Arthritis with Concomitant Therapy (ATTRACT) $(43 / 259(17 \%))$, the pivotal phase 3 trial of infliximab in rheumatoid arthritis. ${ }^{15}$

To our knowledge, this is the longest reported treatment and follow up for an anti-TNF agent in patients with AS. The results show that the clinical benefit seen during the first year of the study was maintained throughout the second year and that infliximab treatment was generally well tolerated during 2 years of treatment. Additional long term studies of infliximab in AS are warranted using larger patient groups.

\section{ACKNOWLEDGEMENTS}

We thank Xenofon Baraliakos for assistance with data management and the preparation of the manuscript. We also thank Scott Newcomer and Michelle Perate of Centocor for their writing and editorial assistance.

This study was supported through partnership with Centocor and Schering-Plough, US; Essex Pharma, Munich, Germany, provided the study drug.

\section{Authors' affiliations}

J Braun, J Sieper, University Medicine Berlin, Campus Benjamin Franklin, Germany

J Braun, J Brandt, Rheumatology Medical Centre Ruhrgebiet, Herne, Germany

J Listing, A Zink, J Sieper, German Rheumatism Research Centre, Berlin, Germany

R Alten, Schlosspark Clinic, Berlin, Germany

G Burmester, Charité Hospital, Humboldt University, Berlin, Germany

E Gromnica-Ihle, Berlin-Buch Hospital, Berlin Germany

H Kellner, Ludwig-Maximilians-University, Munich, Germany

M Schneider, Heinrich-Heine-University, Düsseldorf, Germany

H Sörensen, Immanuel Hospital, Berlin, Germany

H Zeidler, Medical University, Hannover, Germany

The first two authors contributed equally to this paper.

\section{REFERENCES}

1 Wanders A, van der Heijde D, Landewé R, Behier JM, Calin A, Olivieri I, et al. Inhibition of radiographic progression in ankylosing spondylitis (AS) by continuous use of NSAIDs. Arthritis Rheum 2003;48(Suppl):S233.

2 Clegg DO, Reda DJ, Weisman MH, Blackburn WD, Cush JJ, Cannon GW, et al. Comparison of sulfasalazine and placebo in treatment of ankylosing spondylitis: a Department of Veterans Affairs cooperative study. Arthritis Rheum 1996;39:2004-12.

3 Braun J, de Keyser F, Brandt J, Mielants H, Sieper J, Veys E. New treatment options in spondyloarthropathies: increasing evidence for significant efficacy of anti-tumor necrosis factor therapy. Curr Opin Rheumatol 2001;13:245-9.

4 Braun J, Brandt J, Listing J, Zink A, Alten R, Golder W, et al. Treatment of active ankylosing spondylitis with infliximab: a randomised controlled multicentre trial. Lancet 2002;359:1 187-93.

5 Braun J, Brandt J, Listing J, Zink A, Alten R, Burmester G, et al. Long-term efficacy and safety of infliximab in the treatment of ankylosing spondylitis: an open, observational, extension study of a three-month, randomized, placebocontrolled trial. Arthritis Rheum 2003;48:2224-33.

6 Garrett S, Jenkinson T, Kennedy LG, Whitelock H, Gaisford P, Calin A. A new approach to defining disease status in ankylosing spondylitis: the Bath Ankylosing Spondylitis Disease Activity Index. J Rheumatol 1994;21:2286-91.

7 Calin A, Garrett S, Whitelock H, Kennedy LG, O'Hea J, Mallorie P, et al. A new approach to defining functional ability in ankylosing spondylitis: the development of the Bath Ankylosing Spondylitis Functional Index. J Rheumatol 1994;21:2281-5.

8 Jenkinson TR, Mallorie PA, Whitelock HC, Kennedy LG, Garret SL, Calin A, et al. Defining spinal mobility in ankylosing spondylitis (AS). The Bath AS Metrology Index. J Rheumatol 1994;21:1694-8.

9 Ware JE Jr, Sherbourne CD. The MOS 36-item short-form health survey (SF36). Conceptual framework and item selection. Med Care 1992;30:473-83.

10 Medical Outcome Trust. How to score the SF-36 Health Survey, 2nd ed. Boston: Medical Outcome Trust, 1994.

11 Anderson JJ, Baron G, van der Heijde D, Felson DT, Dougados M. Ankylosing Spondylitis Assessment Group preliminary definition of short-term improvement in ankylosing spondylitis. Arthritis Rheum 2001;44:1876-86.

12 Brandt J, Listing J, Sieper J, Rudwaleit $M$, van der Heijde D, Braun J. Development and preselection of criteria for short-term improvement after anti-TNF $\alpha$ therapy in ankylosing spondylitis. Ann Rheum Dis 2004;63:1438-44, doi:10.1136/ard.2003. 016717 [Published Online First 25 Mar 2004].

13 Listing J, Schlittgen R. A nonparametric test for random dropouts. Biometrical Journal 2003:45: 113-27.

14 Baert F, Noman M, Vermeire S, van Assche G, D'Haens G, Carbonez A, et al. Influence of immunogenicity on the long-term efficacy of infliximab in Crohn's disease. N Engl J Med 2003;348:601-8.

15 Maini R, Breedveld FC, Kalden JR, Smolen JS, Furst D, Weisman MH, et al. Sustained improvement over two years in physical function, structural damage, and signs and symptoms among patients with rheumatoid arthritis treated with infliximab and methotrexate. Arthritis Rheum 2004;50:1051-65. 